\title{
Possible Therapeutic Use of Bumetanide in the Treatment of Autism Spectrum Disorder
}

\author{
Sara Kassem, Terry Oroszi ${ }^{*}$ \\ Department of Pharmacology and Toxicology, Boonshoft School of Medicine, Wright State University, Fairborn, OH, USA \\ Email: *terry.oroszi@wright.edu
}

How to cite this paper: Kassem, S. and Oroszi, T. (2019) Possible Therapeutic Use of Bumetanide in the Treatment of Autism Spectrum Disorder. Journal of Biosciences and Medicines, 7, 58-67.

https://doi.org/10.4236/jbm.2019.712006

Received: October 29, 2019

Accepted: December 1, 2019

Published: December 4, 2019

Copyright $\odot 2019$ by author(s) and Scientific Research Publishing Inc. This work is licensed under the Creative Commons Attribution International License (CC BY 4.0).

http://creativecommons.org/licenses/by/4.0/

\begin{abstract}
Autism spectrum disorder (ASD) is a neurodevelopmental disorder. Autism Spectrum Disorder is diagnosed early on in a child's life, anywhere from eighteen to twenty-four months. The disorder is characterized by variable degrees, by difficulties in nonverbal communication, verbal communication, social interaction, repetitive behaviors, and movement. The occurrence of ASD has been increasing globally, with the most recent prevalence studies indicating that they are present in six per one thousand children and one in every sixty-eight people of all ages, with a higher incidence among males, with a ratio of four to one. There is no specific target demographic for Autism Spectrum Disorder, nor is there a cure. Over the last few decades, there have been advancements in treating the symptoms associated with Autism Spectrum Disorder. Among the many different fields of research associated with Autism Spectrum Disorder, Bumetanide has shown to be a promising drug therapy for children suffering from Autism, treating specifically the behavioral symptoms associated with ASD. Bumetanide is forty times more potent than furosemide and is a loop diuretic mainly acting in the ascending limb of the loop of Henle. A clinical trial conducted found a decrease in the Childhood Autism Rating Scale (CARS) score, showing improvement in Autism Spectrum Disorder symptoms, such as repetitive behavior and initiating or participating in the social interaction.
\end{abstract}

\section{Keywords}

Autism, Autism Spectrum Disorders, Bumetanide, Chloride,

Gamma-Aminobutyric Acid, Clinical Trial

\section{Introduction}

Children with ADHD and autism have some similar features, complicating a 
differential diagnosis and could be why Autism spectrum disorder (ASD) was originally diagnosed as an attention deficit disorder [1]. The cause of ASD is not yet known, studies suggest it is a neurodevelopmental disorder with a genetic basis [2]. Early research of an association between autism and epilepsy implied a biological rather than psychogenic factor in the etiology of autism [3]. Individuals suffering from this neurodevelopmental disorder are diagnosed using the Childhood Autism Rating Scale (CARS) [4] [5] [6]. The CARS scale is broken down into fifteen sections, with each one ranging from one to four, with the lower number indicating less impairment. Results from the CARS can range from fifteen to sixty. A non-autistic ranking would be below thirty, and above thirty-seven indicates severe autism [5].

Prevalence of ASD has significantly increased in the past few decades. According to the CDC, ASD has become more prevalent, affecting one in every sixty-eight people of all ages with a higher incidence in males than females, with a ratio of four to one. When specifically considering children, the rate changes to one in one thousand [2]. Individuals suffering from Autism spectrum disorder often suffer from intellectual and/or language impairments [7] [8] [9]. In the 1970 s and 1980s, about one out of every two thousand children had an autism diagnosis. This increase may be attributed to doctors diagnosing autism more regularly, particularly in children with minor problems. The expanded definition refers not only to autism but also to a collection of developmental brain disorders such as Asperger's syndrome, which may also play a role in the increased diagnosis.

Children can be diagnosed as early as 18 months if development delays are severe enough to diagnose; however, more often, a diagnosis occurs when the child is about two years of age [10] [11] [12]. First symptoms of ASD present itself as a language development delay, as well as a disinterest in interacting socially [12] [13]. The physical anomalies in a person with ASD are minor, if any exists; therefore, any individual on the autism spectrum cannot be distinguished merely based on looks. Diagnosing ASD can be difficult; there are no physiological testing that can verify a diagnosis [3] [14].

Autism spectrum disorder is categorized by variable degrees of difficulty with social interaction, nonverbal and verbal communication, and the need for repetition in their day-to-day activities as well as repetitive behaviors [15] [16] [17]. The spectrum groups the severity of ASD into three groups: minor, moderate and sever [18] [19]. The most severe receiving a level 3 and the least severe, requiring the least amount of support, a level 1. Comorbidities include epilepsy, sleep difficulties, and constipation or GI issues [20] [21]. The associated medical conditions are treatable and improve the quality of life for the patient [22]. Because of the associated comorbidities the possibility exists that the presence of important genetic markers, which, if identified, can provide improved diagnoses and genetic subtypes within the autism spectrum [22].

Gamma-aminobutyric acid (GABA) has been shown to influence dopamine activity in the Brain [23]. GABAergic signals are altered in individuals who have 
ASD. GABA is essential in higher cognitive functions and is produced by GABAergic neurons which are reduced in Autism patients [24] [25] [26]. In the nervous system, $\mathrm{Cl}^{-}$gradients are essential in synaptic signaling mediated by the neurotransmitters GABA and glycine. $\mathrm{Cl}^{-}$gradients also play key roles in neuronal growth and development [27] [28] [29]. GABA inhibits adult neurons but excite immature ones because of the higher intracellular chloride concentration leading to depolarizing and often excitatory actions of GABA instead of hyperpolarizing and inhibitory actions [30]. Controlling $\left[\mathrm{Cl}^{-}\right] \mathrm{i}$ can reinstate inhibitory actions of GABA and by doing so open novel therapeutic perspectives in many neurological disorders, such as autism spectrum disorders [30].

Bumetanide is a loop diuretic that acts on the kidney by inhibiting the isoform II of the $\mathrm{Na}^{+}, \mathrm{K}^{+}, 2 \mathrm{Cl}^{-}$(NKCC2) cotransporter in the thick ascending limb of the loop of Henle [31] [32]. When the inhibitory actions of GABA are reinstated novel therapeutic perspectives in many neurological disorders, such as autism spectrum disorders [30]. Bumetanide has been identified as a promising treatment of behavioral symptoms in ASD. Bumetanide can decrease neuronal chloride concentrations and reinstate g-aminobutyric acid (GABA)-ergic inhibition in patients with neurodevelopmental disorders. The excitatory action of GABA on neurons can be reversed by the NKCC1 inhibitor in patients with ASD due to high levels of $\mathrm{Cl}^{-}$in the brain. Bumetanide is part of a class of selective blockers for the NKCC1 chloride importer. Bumetanide acts by blocking NKCC1 cation cotransporter and thus decreases internal Chloride concentration in neurons. In the nervous system, $\mathrm{Cl}^{-}$gradients are essential in synaptic signaling facilitated by the neurotransmitters GABA and glycine. $\mathrm{Cl}^{-}$gradients also play key roles in neuronal growth and development [33]. Researchers found that Bumetanide may have decreased autistic behavior without severe adverse effects in children who suffer from ASD. Ben-Ari et al. [30] investigated the effects of long-term administrations of bumetanide (1 mg daily, three months) in infants with ASD. The effects of the diuretic, were highly significant with the CARS test, and had few side effects. This review will shed light on autism spectrum disorders, similar diagnoses, the pathophysiology of Bumetanide as treatment, pediatric pharmacokinetics, and wrap it up with a clinical trial overview.

\section{Autism Spectrum Disorders}

To fully understand the difference between different diseases under the scope of Autism Spectrum Disorder, the following will be discussed: what is the spectrum and how are people diagnosed? (DSM-V Diagnostic Criteria APA)Differential Diagnoses, distinguishing a particular disease or condition from others that present similar symptoms. The Childhood Autism Rating Scale (CARS) is a15-point rating scale that is used as a test tool to evaluate the changes in symptoms of autistic behavior over time. CARS is typically used to determine changes produced by treatments [34] [35].

Attention-Deficit/Hyperactivity Disorder 
Attention-deficit/hyperactivity disorder is under the scope of autism spectrum disorders and is categorized as a spectrum disorder [1]. Symptoms associated with ADHD include: easily distracted, or overly focused, typically seen with children who have ASD as well as hyperactivity.

\section{Schizophrenia}

Another disease on the spectrum is Schizophrenia. With schizophrenia, hallucinations and delusions are symptoms, which are defining features of the disease, however, are not the same features of autism spectrum disorder. Despite this relationship, [36] did not find an increased diagnosis of schizophrenia in patients diagnosed with autism.

\section{Rhett syndrome}

Autism is a complex behaviorally-defined disorder of the immature brain. It is a syndrome with several genetic and non-genetic causes. Rett (RTT) syndrome is an X-linked disorder that presents in females and is caused by mutations in the MECP2 gene [37]. This syndrome is the only ASDs with a known genetic cause [38]. Research in Rhett Syndrome has increased in recent years because of early reports of its possible association with autism, Rhett syndrome is the lack of social interaction which can be observed in the early toddler years (one to four years old) [39]. However, after this period ceases, most individuals with Rhett syndrome show an improvement in their social communication skills, and no longer exhibit autistic behavior [39].

\section{Fragile $X$ syndrome}

Fragile X syndrome (FXS) is an inherited mental retardation. An expansion of a trinucleotide repeat region in the FMR1 gene found on the $\mathrm{X}$ chromosome is known to be the cause. Research suggests that individuals with FXS are at an increased risk of having autism, although it is still unclear how or why these two disorders are related [40] [41].

\section{Associated Health Risks}

Research conducted by the US Centers for Disease Control demonstrated that children with autism had an increase in health-related difficulties when compared to the expected rates of the medical conditions considered, including gastrointestinal problems, ear and respiratory infections, severe headaches, eczema, migraines, allergies, asthma, and seizures [20]. Mortality in individuals who suffer from ASD usually occurs due to the associated comorbidities, and not from ASD alone [42].

\section{Pathophysiology}

Bumetanide is forty times more potent than furosemide and is a loop diuretic mainly acting in the ascending limb of the loop of Henle. Bumetanide inhibits sodium reabsorption and is often used in individuals who do not respond well to furosemide. Loop diuretics are administered to manage volume surplus on a short-term basis. Bumetanide is typically given to patients with edemas, usually 
accompanying congestive heart failure, as well as hypertension, and kidney disease. (Ward 1984) With a 40-time greater potency than Furosemide, Bumetanide is 80 percent absorbed, with 45 percent secreted in its unchanged form, in urine. The half-life of Bumetanide is anywhere from 60 to 90 minutes after administration. Bumetanide has a rapid onset and a short duration of action. Modes of administration include injections, oral and potentially (still developing) intranasal. ASD has been proposed as a developmental problem involving cation-coupled chloride cotransporters [43].

The action of GABA on neurons, although excitatory, can be reversed by the NKCC1 inhibitor in patients with ASD due to high levels of $\mathrm{Cl}^{-}$in the brain [44]. Bumetanide is a selective blocker of the NKCC1 chloride importer [44]. Bumetanide acts by blocking NKCC1 cation cotransporter and thus decreases internal Chloride concentration in neurons. Bumetanide can decrease neuronal chloride concentrations and may then reinstate g-aminobutyric acid GABAergic inhibition in patients who suffer from a neurodevelopmental disorder [45].

The amount of sodium and water reabsorbed due to ingestion of a loop Diuretic is dependent on the site of activity [46]. Chloride, sodium and water are filtered through the glomerulus of the kidney and later sixty to seventy percent is reabsorbed in the proximal tubule. The loop of Henle sees thirty percent sodium and chloride reabsorption, and ten percent water reabsorption, and the distal convoluted tubule seeing eight percent sodium and chloride reabsorption, with approximately ten to twenty percent water reabsorption. Finally, the last stop for reabsorption is the collecting duct, which sees the least amount of reabsorption with less than One percent of the filtered sodium, chloride, and water which is expelled in the urine. However, Loop diuretics affect sodium and water transport at the loop of Henle, proximal tubule, and the distal tubule [47].

\section{Pediatric Pharmacokinetics}

Due to the administration of Bumetanide to adolescents, it is important to understand the pharmacokinetics of Bumetanide in children. Safety and effectiveness of Bumetanide in pediatric patients below the age of 18 have not been established, but researchers like Lemonnier et al., [48] have steps in place to monitor the safety and efficacy of Butemetide. Butemetide has been extensively utilized since 1975 in adults and since 1986 in children to treat acute and long-term conditions [49]. The use of bumetanide is safe provided that it is accompanied with regular controls to determine possible adverse effects [50]. The process of eliminating Bumetanide appears to be significantly slower in younger patients when compared to adults and notable pharmacokinetic variances in infants and adults are shown to include a reduced clearance and prolonged half-life, which may cause accumulation and to potentially raise toxic levels if dosing intervals are not adjusted [50]. Not enough research has been done to determine how much time is essential for the maturation of loop diuretic elimination in children, older infants, and adolescents. 


\section{Clinical Trial}

In a study conducted by Lemonnier et al. [29]; published in December 2012, fifty-seven children were tested who suffered from autism or Asperger's syndrome. Ages of these children ranged from three to eleven years old. The clinical trial they conducted was a double-blind study with twenty-seven children receiving a placebo for three months, and the other twenty-seven children receiving one mg daily of Bumetanide for three months. Both groups underwent a one-month washout period after the initial three months. Determining the severity of the ASD symptoms was established using CARS (Childhood Autism Rating Scale). Side effects due to treatment were mild in all subjects. Side effects were limited to occasional hypokalemia, which they treated with supplemental potassium.

Patient demographic included twenty-four patients that were nonverbal ten of those twenty-four were treated with a $1 \mathrm{mg}$ daily dose of bumetanide, and fourteen of the twenty-four were given a placebo. Eight patients were able to speak a few words but unable to form sentences (5/3) and twenty-eight were able to speak correctly (15/13).

The results of the study were focused primarily on the CARS scale, secondary to that, the Clinical Global Impressions (CGI), and the ADOS were taken into consideration. CGI is popular to use in clinical trials to observe the level of severity a disease has on an individual. ADOS is an assessment of communication, social interaction, play and imaginative use of tools for persons suspected of suffering from Autism Spectrum Disorder. After ninty days of Bumetanide administration, the treated groups shifted from a CARS score of severe (a score greater than 36.5) to mild or medium severity (a score less than 36.5). However, there was no significant change in the placebo group among day zero and day ninty.

An improvement with minute side effects is shown by the therapeutic index of CGI scores with a decrease from 2.04 to 1.56 . They were also able to observe a $33 \%$ improvement with a placebo, but a seventy-seven percent increase with Bumetanide. Dr. Lemonnier and Dr. Ben Ari are currently working on additional clinical trials in Europe [29].

\section{Conclusions}

Autism spectrum disorder (ASD) is a neurodevelopmental disorder. The disorder is characterized by several behavioral nuances such as difficulties in nonverbal communication, verbal communication, social interaction, repetitive behaviors, and movement. The occurrence of ASD has been increasing globally and to date there is no cure. Over the last few decades, there have been advancements in treating the symptoms associated with Autism Spectrum Disorder. Bumetanide has shown to be a promising drug therapy for children suffering from Autism, treating specifically the behavioral symptoms associated with ASD, based on the CARS scale. This is of great significance in the autism community. ASD has yet to have a proper cause of its occurrence, and the increase in the prevalence of ASD has caught attention internationally. Progression into finding 
new treatments is essential, and Bumetanide is a promising way to get started.

Challenges of the present study field include the lack of established safety protocols in place for human studies involving patients under eighteen. Further clinical trials are required to use Bumetanide effectively as an approved form of treatment. There, unfortunately, does not appear to be an efficient amount of testing to safely allow this to be done globally. Although plenty of animal studies have been conducted to research the effects of Bumetanide on ASD, the clinical trial aforementioned was done on humans at an age important to ASD yielding the most trustworthy results. The good news is that researchers are coming together to address the challenges mentioned in this review. INSAR, the International Society for Autism Research, provides scientific collaboration, mentorship, and education to better the lives of the individuals and families living with autism. The society is working with researchers to find a safety solution.

\section{Conflicts of Interest}

The authors declare no conflicts of interest regarding the publication of this paper.

\section{References}

[1] Mayes, S.D., Calhoun, S.L., Mayes, R.D. and Molitoris, S. (2012) Autism and ADHD: Overlapping and Discriminating Symptoms. Research in Autism Spectrum Disorders, 6, 277-285. https://doi.org/10.1016/j.rasd.2011.05.009

[2] Faras, H., Al Ateeqi, N. and Tidmarsh, L. (2010) Autism Spectrum Disorders. Annals of Saudi Medicine, 295, 30-34. https://doi.org/10.4103/0256-4947.65261

[3] Bryson, S.E. and Smith, I.M. (1998) Epidemiology of Autism: Prevalence, Associated Characteristics, and Implications for Research and Service Delivery. Mental Retardation and Developmental Disabilities Research Reviews, 4, 97-103. https://doi.org/10.1002/(SICI)1098-2779(1998)4:2<97::AID-MRDD6>3.0.CO;2-U

[4] Schopler, E., Reichler, R. and DeVellis, R. (1980) Toward Objective Classification of Childhood Autism: Childhood Autism Rating Scale (CARS). Journal of Autism and Developmental Disorders, 10, 91-103. https://doi.org/10.1007/BF02408436

[5] Schopler, E., Reichler, R. and Rochen Renner, B. (1988) The Childhood Autism Rating Scale. Western Psychological Services.

[6] Tachimori, H., Osada, H. and Kurita, H. (2003) Childhood Autism Rating Scale-Toky Version for Screening Pervasive Developmental Disorders. Psychiatry and Clinical Neuroscience, 57, 113-118. https://doi.org/10.1046/j.1440-1819.2003.01087.x

[7] Estes, A.M., Dawson, G., Sterling, L. and Munson, J. (2007) Level of Intellectual Functioning Predicts Patterns of Associated Symptoms in School-Age Children with Autism Spectrum Disorder. American Journal on Mental Retardation, 112, 439-449. https://doi.org/10.1352/0895-8017(2007)112[439:LOIFPP]2.0.CO;2

[8] Li, G., Jiang, W., Du, Y. and Rossbach, K. (2017) Intelligence Profiles of Chinese School Aged Boys with High-Functioning ASD and ADHD. Neuropsychiatric Disease and Treatment, 13, 1541. https://doi.org/10.2147/NDT.S136477

[9] Thorson, R.T. and Matson, J.L. (2012) Cutoff Scores for the Autism Spectrum Disorder Comorbid for Children (ASD-CC). Research in Autism Spectrum Disorders, 
6, 556-559. https://doi.org/10.1016/j.rasd.2011.07.016

[10] Rogers, S.J. (2000) Diagnosis of Autism before the Age of 3. International Review of Research in Mental Retardation, 23, 1-31. https://doi.org/10.1016/S0074-7750(00)80004-X

[11] Zwaigenbaum, L., Bryson, S.E., Szatmari, P., Brian, J., Smith, I.M., Roberts, W., Vaillancourt, T. and Roncadin, C. (2012) Sex Differences in Children with Autism Spectrum Disorder Identified within a High-Risk Infant Cohort. Journal of Autism and Developmental Disorders, 42, 2585-2596. https://doi.org/10.1007/s10803-012-1515-y

[12] Sandra, M., Muratori, F., Cesari, A., Cavallaro, M.C., Paziente, A., Pecini, C., Grassi, C., Manfredi, A. and Sommario, C. (2005) Course of Autism Signs in the First Year of Life. Psychopathology, 38, 26-31. https://doi.org/10.1159/000083967

[13] Wiggins, L.D., Robins, D.L., Bakeman, R. and Adamson, L.B. (2009) Brief Report: Sensory Abnormalities as Distinguishing Symptoms of Autism Spectrum Disorders in Young Children. Journal of Autism and Developmental Disorders, 39, 1087-1091. https://doi.org/10.1007/s10803-009-0711-x

[14] Grandgeorge, M., Lemonnier, E., Degrez, C. and Jallot, N. (2014) The Effect of Bumetanide Treatment on the Sensory Behaviours of a Young Girl with Asperger Syndrome. BMJ Case Reports, 2014, bcr2013202092.

https://doi.org/10.1136/bcr-2013-202092

[15] American Psychiatric Association (2000) Diagnostic and Statistical Manual of Mental Disorders. 4th Edition, American Psychiatric Association, Washington DC.

[16] Garfin, D.G. and Lord, C. (1986) Communication as a Social Problem in Autism. In: Social Behavior in Autism, Springer, Boston, MA, 133-151. https://doi.org/10.1007/978-1-4899-2242-7_7

[17] Buffington, D.M., Krantz, P.J., McClannahan, L.E. and Poulson, C.L. (1998) Procedures for Teaching Appropriate Gestural Communication Skills to Children with Autism. Journal of Autism and Developmental Disorders, 28, 535-545. https://doi.org/10.1023/A:1026056229214

[18] Jang, J., Dixon, D.R., Tarbox, J. and Granpeesheh, D. (2011) Symptom Severity and Challenging Behavior in Children with ASD. Research in Autism Spectrum Disorders, 5, 1028-1032. https://doi.org/10.1016/j.rasd.2010.11.008

[19] Rellini, E., Tortolani, D., Trillo, S., Carbone, S. and Montecchi, F. (2004) Childhood Autism Rating Scale (CARS) and Autism Behavior Checklist (ABC) Correspondence and Conflicts with DSM-IV Criteria in Diagnosis of Autism. Journal of Autism and Developmental Disorders, 34, 703-708. https://doi.org/10.1007/s10803-004-5290-2

[20] ATT Medical Comorbidities in Autism Spectrum Disorders. http://nationalautismassociation.org/pdf/medicalcomorbiditiesinasd2013.pdf

[21] Mannion, A., Leader, G. and Healy, O. (2013) An Investigation of Comorbid Psychological Disorders, Sleep Problems, Gastrointestinal Symptoms and Epilepsy in Children and Adolescents with Autism Spectrum Disorder. Research in Autism Spectrum Disorders, 7, 35-42. https://doi.org/10.1016/j.rasd.2012.05.002

[22] Bauman, M.L. (2010) Medical Comorbidities in Autism: Challenges to Diagnosis and Treatment. Neurotherapeutics, 7, 320-327.

https://doi.org/10.1016/j.nurt.2010.06.001

[23] Van Kammen, D.P. (1977) g-Aminobutyric Acid (Gaba) and the Dopamine Hypothesis of Schizophrenia. The American Journal of Psychiatry, 134, 138-143.

[24] Cellot, G. and Cherubini, E. (2014) GABAergic Signaling as Therapeutic Target for 
Autism Spectrum Disorders. Frontiers in Pediatrics, 2, 70. https://doi.org/10.3389/fped.2014.00070

[25] Yip, J., Soghomonian, J.J. and Blatt, G.J. (2009) Decreased GAD65 mRNA Levels in Select Subpopulations of Neurons in the Cerebellar Dentate Nuclei in Autism: An in-Situ Hybridization Study. Autism Research, 2, 50-59.

https://doi.org/10.1002/aur.62

[26] Oblak, A., Gibbs, T.T. and Blatt, G.J. (2009) Decreased GABAA Receptors and Benzodiazepine Binding Sites in the Anterior Cingulate Cortex in Autism. Autism Research, 2, 205-219. https://doi.org/10.1002/aur.88

[27] Pizzarelli, R. and Cherubini, E. (2011) Alterations of GABAergic Signaling in Autism Spectrum Disorders. Neural Plasticity, 2011, Article ID: 297153. https://doi.org/10.1155/2011/297153

[28] Tyzio, R., Nardou, R., Ferrari, D.C., Tsintsadze, T., Shahrokhi, A., Eftekhari, S., Khalilov, I., Tsintsadze, V., Brouchoud, C., Chazal, G. and Lemonnier, E. (2014) Oxytocin-Mediated GABA Inhibition during Delivery Attenuates Autism Pathogenesis in Rodent Offspring. Science, 343, 675-679.

https://doi.org/10.1126/science. 1247190

[29] Éric, L., Degrez, C., Phelep, M., Tyzio, R., Josse, F., Grandgeorge, M., Hadjikhani, N. and Ben-Ari, Y. (2012) A Randomized Controlled Trial of Bumetanide in the Treatment of Autism in Children. Translational Psychiatry, 2, e202. https://doi.org/10.1038/tp.2012.124

[30] Ben-Ari, Y., Khalilov, I., Kahle, K.T. and Cherubini, E. (2012) The GABA Excitatory/Inhibitory Shift in Brain Maturation and Neurological Disorders. The Neuroscientist, 18, 467-486. https://doi.org/10.1177/1073858412438697

[31] Asbury, M.J., Gatenby, P.B.B., O’sullivan, S. and Bourke, E. (1972) Bumetanide: Potent New "Loop" Diuretic. British Medical Journal, 1, 211-213. https://doi.org/10.1136/bmj.1.5794.211

[32] Flamenbaum, W. and Friedman, R. (1982) Pharmacology, Therapeutic Efficacy, and Adverse Effects of Bumetanide, a New "Loop" Diuretic. Pharmacotherapy: The Journal of Human Pharmacology and Drug Therapy, 2, 213-222. https://doi.org/10.1002/j.1875-9114.1982.tb03188.x

[33] Du, L., Shan, L., Wang, B., Li, H., Xu, Z., Staal, W.G. and Jia, F. (2015) A Pilot Study on the Combination of Applied Behavior Analysis and Bumetanide Treatment for Children with Autism. Journal of Child and Adolescent Psychopharmacology, 25, 585-588. https://doi.org/10.1089/cap.2015.0045

[34] Matson, J.L. (2007) Determining Treatment Outcome in Early Intervention Programs for Autism Spectrum Disorders: A Critical Analysis of Measurement Issues in Learning-Based Interventions. Research in Developmental Disabilities, 28, 207-218. https://doi.org/10.1016/j.ridd.2005.07.006

[35] Woo, C.C. and Leon, M. (2013) Environmental Enrichment as an Effective Treatment for Autism: A Randomized Controlled Trial. Behavioral Neuroscience, 127, 487. https://doi.org/10.1037/a0033010

[36] Volkmar, F.R. and Cohen, D.J. (1991) Comorbid Association of Autism and Schizophrenia. The American Journal of Psychiatry, 148, 1705-1707.

[37] Amir, R.E., Van den Veyver, I.B., Wan, M., Tran, C.Q., Francke, U. andZoghbi, H.Y. (1999) Rett Syndrome Is Caused by Mutations in X-Linked MECP2, Encoding Methyl-CpG-Binding Protein 2. Nature Genetics, 23, 185.

https://doi.org/10.1038/13810 
[38] Kumar, R.A. and Christian, S.L. (2009) Genetics of Autism Spectrum Disorders. Current Neurology and Neuroscience Reports, 9, 188-197. https://doi.org/10.1007/s11910-009-0029-2

[39] Gillberg, C. (1987) Autistic Symptoms in Rett Syndrome: The First Two Years According to Mother Reports. Brain and Development, 9, 499-501. https://doi.org/10.1016/S0387-7604(87)80072-4

[40] Belmonte, M.K. and Bourgeron, T. (2006) Fragile X syndrome and Autism at the Intersection of Genetic and Neural Networks. Nature Neuroscience, 9, 1221. https://doi.org/10.1038/nn1765

[41] Harris, S.W., Hessl, D., Goodlin-Jones, B., Ferranti, J., Bacalman, S., Barbato, I., Tassone, F., Hagerman, P.J., Herman, K. and Hagerman, R.J. (2008) Autism Profiles of Males with Fragile X Syndrome. American Journal on Mental Retardation, 113, 427-438. https://doi.org/10.1352/2008.113:427-438

[42] Ward, A. and Heel, R.C. (1984) Bumetanide. A Review of Its Pharmacodynamic and Pharmacokinetic Properties and Therapeutic Use. Drugs, 28, 426-464. https://doi.org/10.2165/00003495-198428050-00003

[43] Moore, Y.E., Conway, L.C., Brandon, N.J., Deeb, T.Z. and Moss, S.J. (2019) Developmental Regulation of KCC2 Phosphorylation Has Long-Term Impacts on Cognitive Function. Frontiers in Molecular Neuroscience, 12, 173. https://doi.org/10.3389/fnmol.2019.00173

[44] Schulte, J.T., Wierenga, C.J. and Bruining, H. (2018) Chloride Transporters and GABA Polarity in Developmental, Neurological and Psychiatric Conditions. Neuroscience \& Biobehavioral Reviews, 90, 260-271. https://doi.org/10.1016/j.neubiorev.2018.05.001

[45] Holmes, G.L., Tian, C., Hernan, A.E., Flynn, S., Camp, D. and Barry, J. (2015) Alterations in Sociability and Functional Brain Connectivity Caused by Early-Life Seizures Are Prevented by Bumetanide. Neurobiology of Disease, 77, 204-219. https://doi.org/10.1016/j.nbd.2015.02.015

[46] Oh, S.W. and Han, S.Y. (2015) Loop Diuretics in Clinical Practice. Electrolytes \& Blood Pressure, 13, 17-21. https://doi.org/10.5049/EBP.2015.13.1.17

[47] Eades, S.K. and Christensen, M.L. (1998) The Clinical Pharmacology of Loop Diuretics in the Pediatric Patient. Pediatric Nephrology, 12, 603-616. https://doi.org/10.1007/s004670050514

[48] Lemonnier, E., Villeneuve, N., Sonie, S., Serret, S., Rosier, A., Roue, M., Brosset, P., Viellard, M., Bernoux, D., Rondeau, S. and Thummler, S. (2017) Effects of Bumetanide on Neurobehavioral Function in Children and Adolescents with Autism Spectrum Disorders. Translational Psychiatry, 7, e1056.

https://doi.org/10.1038/tp.2017.10

[49] Sullivan, J.E., Witte, M.K., Yamashita, T.S., Myers, C.M. and Blumer, J.L. (1996) Analysis of the Variability in the Pharmacokinetics and Pharmacodynamics of Bumetanide in Critically Ill Infants. Clinical Pharmacology \& Therapeutics, 60, 414-423. https://doi.org/10.1016/S0009-9236(96)90198-8

[50] Hadjikhani, N., Zurcher, N.R., Rogier, O., Ruest, T., Hippolyte, L., Ben-Ari, Y. and Lemonnier, E. (2015) Improving Emotional Face Perception in Autism with Diuretic Bumetanide: A Proof-of-Concept Behavioral and Functional Brain Imaging Pilot Study. Autism. The International Journal of Research and Practice, 19, 149-157. https://doi.org/10.1177/1362361313514141 